\title{
Economia versus intimidade: uma alternativa via as sociologias de Viviana Zelizer e Eva Illouz
}

\author{
Economy versus intimacy: an alternative route to sociology Viviana Zelizer \\ and Eva Illouz
}

\begin{abstract}
Alyson Freire ${ }^{1}$
Resumo: $\mathrm{O}$ artigo problematiza as pré-noções correntes acerca das conexões entre relações íntimas e relações econômicas, a partir de alguns aportes colhidos nos trabalhos das sociólogas contemporâneas Viviana Zelizer e Eva Illouz. Nessas autoras, podemos encontrar relevantes subsídios teóricos e empíricos para uma abordagem sociológica, nãoreducionista e não dicotômica, dos vínculos entre intimidade, cultura e economia, de sorte a suscitar uma perspectiva crítica e questionadora das visões convencionais e fatalistas que antagonizam mercado e vida emocional dos indivíduos como se fossem realidades essencialmente antitéticas e contrárias. As análises de Zelizer e Illouz oferecem, ainda, conceitos e argumentos profícuos para reinscrever o lugar dos afetos e das emoções no plano da análise sociológica.
\end{abstract}

Palavras-chave: Intimidade, Economia, Viviana Zelizer. Eva Illouz. Nova Sociologia Econômica.

\begin{abstract}
The article discuss the common pre-notions about the connections between intimate relationships and economic relations from some texts searched in works of the contemporary sociologist's Viviana Zelizer e Eva Illouz. In these authors, we can find theoretical and empiric relevant elements to do a non-reductionist and non-dichotomous sociological analysis of the relations between intimacy, culture and economy in order to

\footnotetext{
${ }^{1}$ Professor de Sociologia do Instituto Federal de Educação, Ciência e Tecnologia do Rio Grande do Norte (IFRN) e Pesquisador do Núcleo de Estudos Críticos em Subjetividades Contemporâneas e Direitos Humanos, da Universidade Federal do Rio Grande do Norte. Contato: alyson.freire@ifrn.edu.br
}

Latitude, Vol. 8, no 2, pp. 255-287, 2014

DOI: https://doi.org/10.28998/2179-5428.20140203 


\section{Economia versus intimidade: uma alternativa via as sociologias de Viviana Zelizer e Eva Illouz}

create a critical and questioner perspective of the conventional and fatalistic views that antagonize the market and the emotional life of individuals as if they were essentially antithetic and contrary realities. The works of Zelizer e Illouz also offer the concepts and arguments to rewrite the place of affections and emotions in the domain of sociological analysis.

Keywords: Intimacy. Economy. Viviana Zelizer. Eva Illouz. New Economic Sociology.

\section{Introdução}

À primeira vista, pode-se pensar que sentimentos, emoções e afetos nada ou muito pouco tem a ver com a sociologia. Tais "objetos", por assim dizer, não se afeiçoam à visão comum cultivada a propósito do campo de problemas e preocupações característicos desta disciplina. Para a sociologia, uma ciência que forja sua identidade epistemológica apoiada no estudo de fenômenos sociais cuja existência residiria "fora das consciências individuais", interessaria, antes de qualquer coisa, as questões do âmbito da racionalidade. As questões "subjetivas" da vida afetiva e das relações interpessoais, por sua vez, tratar-se-iam, na melhor das hipóteses, de temas estrangeiros, residuais, menores, ou mesmo "não-sociológicos".

Bastaria consultar os principais manuais e dicionários da disciplina para constatar a ausência de verbetes como "afetos", "emoções" e "sentimentos" no léxico disciplinar canônico. O lugar legítimo da investigação das emoções e dos sentimentos residiria, assim, em saberes vizinhos, como a psicologia, a psicanálise e a filosofia, mas jamais no escopo próprio à ciência da sociedade.

Contudo, esta visão caricata e estreita, que alimenta a opinião corrente sobre a sociologia e o seu campo de investigação, não se sustenta em absoluto. Já nos clássicos da disciplina encontramos exemplos contundentes e entusiasmados com respeito à abordagem sociológica desses temas supostamente elusivos ligados à vida emocional dos indivíduos. Citemos: a coqueteria, a gratidão e a fidelidade em Simmel (2008); ou o amor sexual e a constituição do erotismo como uma esfera de valor autônoma na cultura moderna em Max Weber (2002) e, finalmente, em Durkheim (2000), suas investigações acerca do conteúdo social e emocional das crenças e das formas de classificação do mundo, expresso 
Alyson Freire

em conceitos como "consciência coletiva", "efervescência" e "solidariedade".

Se avançarmos no espectro do tempo da produção sociológica, as referências a propósito da esfera íntima da vida social se multiplicam: sociólogos consagrados como Norbert Elias (1994; 2001), Anthony Giddens (1994), Zygmunt Bauman (2004), Niklas Luhmann (1991), reservaram em suas obras um lugar de destaque ao tratamento sociológico das emoções e dos sentimentos, articulando-os no interior de seus projetos teóricos e motes de maior interesse. Cumpre destacar, também, as pesquisas contemporâneas de uma autora de grande imaginação sociológica, a saber: Arlie R. Hochschild (1983), grande expoente da sociologia das emoções. Seus trabalhos sobre o papel da gestão das emoções e a construção de regras expressivas e corporais para apresentar e manter uma determinada imagem de si nas interações no mundo do trabalho e na vida familiar constituem, certamente, um referência incontornável para qualquer investigação sociológica das emoções.

Não obstante tais referências, a vida emocional e as relações íntimas ainda são concebidas como questões cuja relevância sociológica e explicativa é analítica e teoricamente subestimada, em especial no tocante à abordagem de determinados campos de problemas e práticas do mundo social. Por isso, muitas vezes, as emoções somente ganham lugar como apêndices ou como um dos polos dicotômicos no interior de esquemas teóricos duais, os quais, de modo intencional ou involuntário, acabam por transformar as emoções no "outro" da racionalidade, isto é, fenômenos do campo da irracionalidade das relações sociais. Aliás, mesmo após os esforços criativos e reconstrutivos do "novo movimento teórico de síntese" (ALEXANDER, 1987) em superar os sólidos dualismos que estruturaram fortemente a análise sociológica no decorrer do século $X X$, podemos afirmar que a dicotomia racionalidade e emoções, isto é, que polariza como antinomias e categorias exclusivas fenômenos pertencentes à racionalidade e fenômenos pertencentes ao campo dos sentimentos e da vida afetiva dos indivíduos, usufrui, ainda, de uma vigorosa persistência no pensamento sociológico.

A economia é o âmbito das atividades humanas em que dita dicotomia talvez possua mais força e naturalidade. Quer dizer, em que os conteúdos emocionais e as ligações afetivas das relações econômicas sejam concebidos como tendo uma menor influência e importância causal no que 


\section{Economia versus intimidade: uma alternativa via as sociologias de Viviana Zelizer e Eva Illouz}

diz respeito a sua explicação. Pensemos acerca do lugar teórico destinado aos conteúdos emocionais e afetivos no estudo e abordagem da vida econômica capitalista, isto é, na análise de suas instituições, na formação e evolução de mercados específicos, suas formas e métodos de organização do trabalho e de acumulação, etc.. No que diz respeito à história das ciências sociais em geral e da sociologia em particular, a dicotomia racionalidade e emoções possui, inclusive, um papel estruturante na delimitação dos fenômenos empíricos aptos e legítimos à investigação econômica e ao trabalho sociológico ${ }^{2}$. Mais do que simplesmente dicotomias e polarizações abstratas e disciplinares, podemos identificar nos estudos da vida econômica capitalista uma visão valorativa e moral com respeito às relações dos fatos econômicos com os afetos e com a vida emocional dos indivíduos.

Nesse sentido, no tocante ao entendimento do desenvolvimento e dinâmica da economia e do mercado capitalistas, "fatores irracionais" como afetos, relações interpessoais e cultura contribuem muito pouco para a uma correta elucidação científica desses fenômenos, costuma-se pensar. O mercado seria, desse modo, uma esfera autônoma, independente em suas propriedades quanto aos outros aspectos e ingredientes da vida social. Seus determinantes e pressupostos são, portanto, internos ao próprio mercado e à lógica econômica capitalista, isto é, definidos pela racionalidade de atores anônimos e forças impessoais cujos sentimentos ou crenças culturais compartilhadas são sobrepujados, como base motivacional da ação, pelo cálculo dos interesses e oportunidades. Esta visão não é privilegio da ciência econômica, verdadeira "fortaleza positivista", como diria Albert O. Hirschman (1981, p. 25), mas encontra, também, abrigo na sociologia e em outras ciências sociais:

Por muito tempo a visão dominante dos sociólogos, antropólogos, cientistas políticos e historiadores tem

\footnotetext{
2 Tanto que no assim chamado pacto parsoniano (PARSONS \& SMELSER, 1956; PARSONS \& KROEBER, 1958), a divisão de trabalho entre sociologia, economia e outras ciências sociais, a primeira seria a responsável pela investigação dos fenômenos e processos mais "racionais", como o mercado e a formação de preços, contratos, firmas e bancos, enquanto a segunda ficaria com a análise dos fenômenos e processos mais "irracionais", tais como a religião, a família, os valores culturais, o suicídio, o crime, os conflitos sociais, etc..
} 


\begin{abstract}
Alyson Freire
sido a de que esse comportamento se encontrava profundamente imerso nas relações sociais em sociedades pré-mercantis mas se tornou muito mais autônomo com o advento da modernização. Essa visão interpreta a economia como uma esfera diferenciada e cada vez mais separada na sociedade moderna, com transações econômicas não mais definidas por obrigações sociais ou de parentesco, mas por cálculos racionais de ganho individual (GRANOVETTER, 2007, p. 03).
\end{abstract}

Contudo, como quase todas as dicotomias que estruturam o pensamento, há também aqui um fundo normativo. A questão não se encerra, com efeito, apenas em seus aspectos analíticos e conceituais. Há uma polarização ou juízo moral de fundo, fortemente presente na sociologia e em outras ciências sociais, que visa justificar, ainda que tacitamente, uma determinada concepção normativa sobre a natureza do mercado e suas implicações para a sociedade e os indivíduos. Por exemplo, a noção liberal clássica que toma o mercado como o lugar das virtudes da autonomia individual e uma instituição produtora de paz e harmonia social, ou, em contrapartida, noções mais céticas e críticas que enxergam no mercado os perigos corrosivos da impessoalidade e do cálculo, assim como os vícios do egoísmo e da ganância, de modo que todo e qualquer vínculo emocionalmente significativo resulta ameaçado sob sua influência.

Em linhas gerais, Marx, Durkheim, Simmel e Weber possuem um ponto em comum neste particular, o qual, diga-se, os aproxima no tocante as suas críticas do capitalismo moderno, qual seja; o temor e as denúncias contra a influência despersonalizadora e os efeitos patológicos do mercado sobre a vida individual e sobre os laços sociais significativos. Se é verdadeiro, por um lado, que podemos encontrar nos clássicos diversos e ricos elementos para o estudo rigoroso dos fatos econômicos ${ }^{3}$, por outro, também é verdadeiro que neles vigoram uma forte e impregnante visão segunda a qual o mercado e a vida econômica capitalista em geral possuem

${ }^{3}$ Sobre as possibilidades analíticas do estudo da vida econômica em Weber e Durkheim, ver: RAUD-MATTEDI (2005). Sobre as possibilidades analíticas da sociologia das formas sociais de Simmel para o estudo dos fenômenos econômicos, ver LAGENOHL (2010). 


\section{Economia versus intimidade: uma alternativa via as sociologias de Viviana Zelizer e Eva Illouz}

uma propensão nefasta e destrutiva capaz de erodir, sufocar e corromper os laços, valores e qualidades não-mercantis, os quais, segundo o seu juízo, são imprescindíveis para a existência de uma sociedade mais justa e de uma individualidade plena.

Desse ponto de vista, o problema não é tanto de avaliar a maior ou menor presença das "questões pertencentes às relações afetivas e à vida emocional dos indivíduos" na sociologia, ou de como tornar estas "objetos" legítimos desta última. O verdadeiro problema consiste, a nosso ver, em como articular, teórica e empiricamente, as emoções e as relações afetivas com categorias, pressuposições e temas fundamentais da sociologia sem que as primeiras sejam tratadas como aspectos residuais ou, então, como uma reserva moral de autenticidade que urge preservar das poderosas e arrasadoras forças macrossociais e históricas do mercado e da economia.

Buscaremos como alternativa para problematizar as dicotomias presentes tanto no senso comum quanto na análise sociológica - entre relações íntimas e relações econômicas e entre racionalidade e emoções, alguns aportes nos trabalhos de duas importantes autoras contemporâneas, quais sejam: Viviana Zelizer e Eva Illouz. A primeira é uma representante da corrente chamada Nova Sociologia Econômica e a segunda se inscreve no âmbito mais geral de uma sociologia da cultura.

O que aproxima ambas as autoras em seus trabalhos sociológicos, além de tomarem a sociedade norte-americana dos séculos XIX e XX como campo de estudo para suas pesquisas e reflexões, é o interesse recíproco de estudar as intersecções, formadas na experiência social dos agentes com as instituições, os credos culturais e as práticas econômicas que caracterizam a sociedade moderna, entre racionalidade e o campo das emoções e sentimentos humanos. No trabalho dessas duas autoras, podemos apreender como as relações íntimas e os afetos em suas intersecções com as transações e instituições econômicas e comerciais constituem importantes chaves explicativas para a abordagem sociológica, de uma maneira nãoreducionista e não dicotômica, das relações entre intimidade, economia e cultura, de sorte a enfrentar visões moralizantes e fatalistas, as quais, em virtude de suas suposições, antagonizam de modo reificante mercado e vida emocional dos indivíduos como que se tratassem de universos sociais inteiramente antitéticos.

\section{A Nova Sociologia Econômica}


Alyson Freire

Antes de avançar nos trabalhos de Viviana Zelizer e Eva Illouz e na perspectiva teórica que essas sociólogas lançam sobre o lugar da vida emocional dos indivíduos na vida econômica das sociedades modernas, cumpre situar a primeira de nossas autoras na abordagem teóricometodológica mais ampla em que suas pesquisas estão inscritas, isto é: a Nova Sociologia Econômica. Descreveremos em suas linhas gerais para o esclarecimento do leitor não-familiarizado com essa nova corrente sociológica.

A emergência da Nova Sociologia Econômica - doravante NSE nos Estados Unidos no início dos anos 80 do século $\mathrm{XX}^{4}$ recupera e prolonga um antigo debate entre sociologia e ciência econômica ${ }^{5}$. Contudo, de um modo mais direto e íntimo do que, desde os clássicos, muitos sociólogos e economistas estariam dispostos a admitir, sobretudo os que abraçaram o pacto parsoniano. A NSE consiste em um ressurgimento da sociologia econômica dos clássicos. Porém, dessa vez, com um ímpeto mais disciplinarmente propositivo a fim de construir um novo marco analítico dos fatos e processos econômicos à luz dos conceitos e métodos da investigação sociológica.

\footnotetext{
${ }^{4}$ Embora NSE possua suas raízes e principais nomes em solo norte-americano, o investimento contemporâneo da sociologia sobre o campo da economia não se encerra nas fronteiras dos Estados Unidos. Outros países destacam-se, inclusive, com particularidades teórico-metodológicas relevantes, neste empreendimento. Em especial, a França com Phillip Steiner e sua sociologia do conhecimento, a "economia das convenções" de Boltanski e Thevenot, Michel Callon com sua "teoria-do-ator-em-rede" e suas ideias de performatividade, a etnografia fenomenológica de Knorr-Cetina, entre outros. Para um balanço das diversas feições assumidas pela Sociologia Econômica nos Estados Unidos e Europa, ver: SWEDBERG (2004).

${ }^{5} \mathrm{O}$ desenvolvimento da Sociologia durante e na virada do século XIX, foi marcado, entre outros fatores, por um direto e crítico debate com alguns dos pressupostos da teoria econômica clássica; mais precisamente com aqueles oriundos da Economia Política de Adam Smith, do Utilitarismo de John Stuart Mill, do Marginalismo, da teoria econômica da Escola Austríaca de Carl Menger, entre outros. Os clássicos da disciplina, Marx, Durkheim, Weber e Simmel, se debruçaram, com empenho, não apenas sobre as atividades e processos econômicos cruciais para a formação da sociedade moderna mas mantiveram, ao longo do processo de elaboração de suas teorias e pensamento, diálogos pertinentes e fecundos com teorias e escolas econômicas de suas épocas.
} 


\section{Economia versus intimidade: uma alternativa via as sociologias de Viviana Zelizer e Eva Illouz}

Os interlocutores e adversários erguidos para delinear por contraste a identidade desse novo ramo da análise sociológica - vão desde a Economia Neoclássica, da Nova Economia Institucional à "velha" Sociologia Econômica dos anos 1950. A NSE entra em cena em meio a um contexto de descontentamento, aproximação e intenso debate com respeito às formulações de explicações alternativas e críticas a alguns dos pressupostos fundantes dessas tradições em economia e em sociologia (STEINER, 2006).

A NSE é, portanto, um desdobramento analítico deste efervescente contexto em que, no decorrer dos anos 1980, o campo da ciência econômica encontrava-se interna e externamente pressionado. De um lado, a busca por novas formas de abordagem e explicação dos processos econômicos, e, de outro, o início de uma reação mais organizada e contundente por parte dos sociólogos contra o "imperialismo acadêmico" da ciência econômica sobre os “objetos" estudados até então pela sociologia (LOPES JUNIOR, 2002, p. 39).

No processo de avaliação e reavaliação dos métodos de investigação e esquemas de análise estabelecidos acerca dos fenômenos econômicos, as pesquisas sociológicas sobre vida econômica, desenvolvidas pela NSE, visavam questionar os pressupostos instrumentais das preferências individuais e das interações entre jogadores. Para isso, novas categorias, métodos e pressuposições ausentes ou insuficientemente levadas em consideração nos modelos neoclássicos ${ }^{6}$ foram, então, alçados a um patamar explicativo de destaque, tais como; o papel das relações, redes e estruturas sociais, do poder, das relações de gênero, do direito, da negociação, entre outros, para pensar os fatos econômicos (ZELIZER, 2008).

Para os desbravadores da NSE, como o consagrado Mark Granovetter em seu texto fundacional7, os fatos econômicos não ocorrem num vazio, mas dentro de um marco social ${ }^{8}$ composto por relações sociais

\footnotetext{
${ }^{6}$ Este artigo não irá se deter, com mais afinco, no diálogo crítico que NSE estabelece com a análise econômica tradicional e neoclássica. Para maiores detalhes das rupturas, avanços e influências envolvidas na NSE e com as perspectivas teóricas do chamado mainstream econômico, ver: LOPES JUNIOR (2002).

${ }^{7}$ GRANOVETTER (p.481-510, 1985), tradução em português: GRANOVETTER (2007).

8 Juntamente com a noção de redes sociais (network analysis), a ideia de imersão ou enraizamento - embeddedness - da ação econômica, trabalhada e retirada da obra
} 
Alyson Freire

variadas que envolvem confiança, instituições, organizações e redes interpessoais concretas. (GRANOVETTER, 2007). Ou, nos termos de Richard Swedberg, outra referência central da NSE: "Outro modo de expressar o problema seria dizer que todos os fenômenos econômicos são sociais por sua natureza; estão enraizados no conjunto ou em parte da estrutura social"' (SWEDBERG, 2004, p. 8).

O cerne da crítica da NSE, em seus primeiros anos, é dirigido contra a tese segunda a qual a economia seria uma esfera ou sistema completamente autônomo - tese, como veremos mais à frente, presente nos trabalhos Zelizer e Illouz. Outro importante flanco de ataque da NSE dirige-se contra a ideia de que os fatos econômicos poderiam ser explicados unicamente pelas motivações oriundas de um suposto comportamento universal do ator movido única ou principalmente pela maximização de seus interesses particulares. Para NSE, nem as leis abstratas, descoladas do restante do mundo social que regem as transações, nem a pura racionalidade do ator dariam conta da complexidade de fatores e motivações não-econômicas que atuam e empoderam a ação econômica e o comportamento dos atores 9 .

Com base na tese acima, podemos elencar alguns dos aportes que conferem alguma estabilidade e identidade a perspectiva de análise a partir da qual a NSE pretende sustentar o seu programa de investigação da vida econômica numa chave sociológica: 1) a esfera econômica é socialmente construída, conforme as estruturas e redes sociais em que os atores estão

Karl Polanyi (2000), formam a base do esquema de análise de Mark Granovetter, o qual inspirou um conjunto de trabalhos na NSE calcados na ideia de construção social dos mercados.

${ }^{9}$ Em tempo, dita empresa crítica dos postulados clássicos e dominantes da ciência econômica, obviamente, não se restringe nem se iniciou com a NSE. Além dos clássicos da sociologia, como já dito anteriormente, podemos encontrar, nas ciências sociais, uma interessante perspectiva crítica dirigida contra a "ideologia econômica" - e sua naturalização no ocidente moderno. As obras do antropólogo Louis Dumont (2000) e do historiador e antropólogo econômico Karl Polanyi (2000) constituem exemplos notáveis a esse respeito. Em ambas, a crítica histórica da reificação e da sedimentação da crença na autonomia adquirida pela economia face ao conjunto das relações sociais, à política e à cultura em particular, ocupam, com efeito, o plano principal da análise para uma gênese histórica da categoria econômica no pensamento moderno e na vida social moderna. 


\section{Economia versus intimidade: uma alternativa via as sociologias de Viviana Zelizer e Eva Illouz}

inseridos; 2) os esquemas culturais compartilhados são importantes para definição dos conteúdos e estratégias da ação econômica; 3) a racionalidade, além de situada, é um tipo de comportamento entre outros, sendo, necessário, portanto, tomá-la mais como um objeto de análise do que como um pressuposto da análise, e, finalmente, 4) as lutas pelo poder entre instituições, organizações da sociedade civil e classes sociais exercem um poder de coordenação e regulamentação das atividades econômicas. Esses pressupostos caracterizam diferentes enfoques teóricos da NSE e abrem diferentes trilhas de pesquisa (WANDERLEY, 2002, p.26).

Se o enfoque da estrutura social e o enfoque da política possuem, respectivamente, em Mark Granovetter e Neil Fligstein (2001) os seus nomes mais consagrados, o enfoque cultural na NSE, por sua vez, tem justamente em Viviane Zelizer sua principal referência.

Dessa maneira, percebe-se que, ao invés de uma ruptura explícita e radical com a economia, a NSE assume como finalidade a tarefa de demonstrar a inadequação e a estreiteza dos esquemas analíticos sustentados na ideia do homo economicus, isto é, do homem naturalmente inclinado ao ganho e autointeresse, assim como de explicações que dispensam a análise da estrutura social e dos constrangimentos e mecanismos sociais variados sobre os processos econômicos. Por outro lado, isso não significa que se deva substituir, em absoluto, tais esquemas de análise pelo modelo do homo sociologicus hipersocializado (GRANOVETTER, 2007).

Nos últimos anos, a NSE se notabiliza, com efeito, pela busca por novos enfoques teóricos e o diálogo crítico com outras tradições e perspectivas sociológicas e econômicas, de sorte que essa corrente, nos últimos anos, assumiu diversas formas de abordagens para além do seu modelo até então mais consagrado, o da análise das redes sociais (SWEDBERG, 2004).

Em que pese à variedade de novas perspectivas que formam hoje essa corrente teórica, esses diferentes esforços se conectam num só; o mesmo que mobilizou incansavelmente Max Weber e sua obra, qual seja: estabelecer e analisar os vínculos que unem o econômico com outros aspectos da vida social. Ou, numa linguagem mais fiel ao autor da Ética Protestante e o Espírito do Capitalismo, estabelecer as conexões de sentido e as afinidades eletivas da economia com outras ordens e poderes sociais, com a finalidade de compreender e explicar como os fatos econômicos moldam e 
Alyson Freire

afetam fatos de outras esferas de atividade e são, por sua vez, também, moldados e afetados por essas esferas - fenômenos "economicamente condicionados" e "economicamente relevantes", respectivamente (WEBER, 2006, p. 31-2; SWEDBERG, 2005).

No esforço de reintroduzir as relações econômicas numa totalidade social, e, assim problematizar as fronteiras entre o que o seria o "econômico" e "não-econômico", complexificando, assim, as motivações do agir econômico, a NSE coloca em questão uma visão disciplinar e departamentalizada de conceber determinados âmbitos da atividade social como antagônicos e autônomos em si mesmos. Essa ideia, como veremos mais a frente, será fundamental nos trabalhos de Viviana Zelizer e Eva Illouz.

A NSE oferece, com efeito, um ângulo alternativo para lidar e reconsiderar as fronteiras arbitrárias e pressuposições que pesam tanto na forma de conceber e observar as trocas econômicas e o comportamento econômico dos agentes na vida real quanto no modo de analisá-los e explicá-los. É precisamente isso que pretendemos explorar neste artigo, valendo-se da obra de duas importantes sociólogas contemporâneas, Viviana Zelizer e Eva Illouz.

\section{Zelizer: Economia, Moralidade e Intimidade}

A obra de Zelizer não apenas desafia os enfoques convencionais da Economia como obriga uma maior abertura da agenda de pesquisa e de interesses da NSE em relação aos seus primeiros estudos e temáticas, demasiadamente concentrado no tema das redes sociais e das firmas e organizações (ZELIZER, 2009; 2010).

A obra da socióloga argentina Viviana Zelizer representa um exemplo incisivo e original de como abordar e superar um dos maiores tabus da vida corrente, isto é, o de que economia e intimidade devem permanecer separadas. Os estudos de Zelizer sobre como relações econômicas e laços íntimos interagem nas relações sociais aportam uma importante crítica contra as pré-noções que polarizam a esfera das trocas econômicas em relação a outras esferas da vida social. Pré-noção expressa na crença douta e corrente de que o econômico, por meio do dinheiro e do mercado, corrompe e impede a intimidade e a autenticidade das relações interpessoais e dos sentimentos. 


\section{Economia versus intimidade: uma alternativa via as sociologias de Viviana Zelizer e Eva Illouz}

As sociedades mercantis e monetarizadas capitalistas vivem um poderoso e dramático dilema, cujo epicentro é a definição dos significados morais dos termos das transações econômicas, sobretudo com respeito às implicações e distinções morais relacionadas com a condução da atividade econômica em geral e com o estatuto do uso do dinheiro em particular no interior das relações interpessoais que envolvem atenção, afetos e intimidade. Não por acaso, o pensamento social clássico concebe o dinheiro como um instrumento essencial no processo de racionalização da sociedade moderna (ZELIZER, 1994).

Se as interpretações sociais clássicas da modernidade destacam o papel homogeneizador e objetificante da economia monetária, em que os significados qualitativos da vida acabam por se reduzir pela universalização do dinheiro a medidas e padrões quantitativos abstratos, Zelizer, por sua vez, opta por seguir um caminho distinto e peculiar. Sem negar a centralidade sistêmica assumida pelo dinheiro, Zelizer, no entanto, decide ler a sua penetração na vida cotidiana sob um viés mais relacional e atento ao que de fato as pessoas fazem nas interações sociais e trocas econômicas que envolvem, juntamente com outros ingredientes da vida social, o uso de dinheiro.

Para Zelizer, a vida social moderna é atravessada por situações em que os indivíduos veem-se impelidos a estabelecer equivalências monetárias, inclusive a propósito daquilo que consideram, moralmente, como inalienável do ponto vista da definição de um valor de troca. Numa pesquisa sobre a formação histórica do mercado de seguros de vida, Zelizer (1983) estudou como a aceitação social dessa indústria, e o seu crescimento nos Estados Unidos, exigiu um conjunto de estratégias de convencimento cujo objetivo era suscitar nos consumidores uma reformulação dos sentidos morais acerca da sacralização da vida humana. Desse modo, o mercado de seguros de vida esforçou-se em transformar o processo de atribuição de valores e preços monetários à vida no resultado de uma preocupação genuína e, ao mesmo tempo, numa garantia com respeito ao futuro dos entes queridos, e, com isso, se desvencilhar de uma compreensão calculista, sintomática de uma mercantilização insensível, quantitativa e funesta a propósito do valor da vida e da morte dos indivíduos.

É esta tensão entre o econômico e aspectos supostamente inalienáveis e inegociáveis da vida e das relações humanas que figura, por assim dizer, no coração do empreendimento sociológico de Zelizer. A 
autora explorou dita tensão em diversos estudos, entre os quais se destacam: o já mencionado estudo sobre o processo de aceitação social dos seguros de vida (1983), o mercado de adoção de crianças (1985), as doações de caridade (1994), os cuidados pessoais e litígios familiares e afetivos (2011).

Estamos diante, portanto, de uma sociologia preocupada com o papel da cultura, dos valores e da afetividade na dinâmica e estruturação dos mercados, pois o estabelecimento de valores mercantis e monetários à bens considerados culturalmente inalienáveis mobilizam e colidem, irremediavelmente, com os códigos de moralidade e de sentimentos dos indivíduos. Esse último ponto pode ser observado, de forma latente, na evolução do moderno "mercado de crianças" para adoção.

Conforme Zelizer (1985), o que ocorreu, como condição indispensável, para a substituição e condenação da prática de adoção para o trabalho infantil não foi simplesmente um refinamento dos mecanismos instrumentais do mercado para maximizar o valor monetário das crianças. Antes, e fundamentalmente, foi um processo de transformações socioculturais nas famílias e no estatuto simbólico da criança concebido como um ser "sem preço", isto é, que se define não mais por sua utilidade econômica para o trabalho e para o sustento material da família adotiva, mas em termos de seu valor afetivo inestimável para as famílias que irão adotá-la.

Os mercados não são, portanto, impermeáveis às mudanças sociais e aos processos culturais de significação e sentido. Estes são, muitas vezes, os vetores de sua transformação e os alicerces de seu funcionamento, como nos mostra, com propriedade e originalidade, Zelizer a respeito da evolução do mercado de crianças nos EUA.

Análises como essa suscitam inquietações capazes de redescrever analiticamente e embaralhar os modos de pensamento dualistas e purista pelos quais nos acostumamos a pensar e abordar as relações entre economia, afetividade e moralidade. Nesse sentido, Zelizer investe na abordagem de situações históricas e diferentes formas de associação e relações sociais em que as atividades econômicas, processos culturais, relações de intimidade e questões morais se misturam e colidem, sem deixar de atentar, com efeito, ao modo como os atores sociais e as instituições negociam os significados e estabelecem limites e parâmetros de legitimidade e justificação desses relacionamentos híbridos de afeto, 


\section{Economia versus intimidade: uma alternativa via as sociologias de Viviana Zelizer e Eva Illouz}

direito, moralidade e economia. A esse propósito, em suas obras mais recentes, litígios sobre os direitos judiciais e econômicos vinculados a relacionamentos íntimos variados constituem um dos principais campos de investigação empírica de suas análises (ZELIZER, 2011).

Valendo-se de suas próprias palavras, podemos afirmar, então, que o seu olhar recai "sobre como as transações íntimas de fato desenrolam-se, notadamente nas áreas de união afetiva, relações de cuidado e vida familiar" (ZELIZER, 2011, p. 15).

Para acompanhar e entender como e sob que condições as pessoas combinam transações econômicas e articulam sentidos em suas relações sociais íntimas, Zelizer analisa uma ampla variedade de práticas sociais rotineiras e interações sociais - muitas delas objetivadas em processos judiciais - concernentes às trocas econômicas e à intimidade dos indivíduos, tais como: presentes entre parceiros conjugais, pagamentos por companhia e por relações sexuais, empréstimos entre familiares, remuneração de cuidadores de crianças e idosos, os limites éticos na relação entre terapeutas e pacientes, litígios judiciais sobre herança, divórcio e indenização entre filhos, ex-cônjuges e patrões e empregadas domésticas, o uso de moedas locais, são alguns dos exemplos estudados pela socióloga. (ZELIZER, 2011).

Zelizer traz à baila, com efeito, pertinentes e elucidativos exemplos de laços humanos não-mercantis mediados monetariamente a partir de atividades, transações e situações sociais que, a um só tempo, contradizem as teses da oposição e antagonismos inerentes entre economia e intimidade, e, ao mesmo tempo, exprimem como estas últimas coexistem e conectam-se no cotidiano das pessoas. Como se pode notar, sua sociologia e sua crítica aos esquemas teóricos convencionais da economia possuem uma rigorosa consistência empírica.

Como uma boa socióloga racionalista, Zelizer adota uma atitude de suspeita e desconfiança a propósito da evidência dos modos de pensar que normalmente usamos acerca das relações entre economia, intimidade e moralidade. Mais precisamente, no campo das relações entre práticas comerciais e intimidade. Ela problematiza analítica e empiricamente as construções e concepções que pré-constróem e fundamentam a percepção na vida social e no senso comum douto da ciência este dilema capital das sociedades de economia monetária, a saber: a relação entre economia e laços afetivos enquanto uma oposição inconciliável. Quer dizer, como se 


\begin{abstract}
Alyson Freire
racionalidade, relações econômicas, dinheiro e mercado, de um lado, e, relações interpessoais significativas que envolvem afetos, sentimentos e intimidade, de outro, tivessem estatutos de realidade e éticos próprios e antagônicos (ZELIZER, 2009).

Para Zelizer, portanto, a divisão do mundo em dois domínios de realidade e princípios éticos incompatíveis e rivais, base daquela tensão capital entre economia e intimidade, entendidas como relações impessoaisracionais e relações expressivos-significativas, respectivamente, não é apenas uma questão trivial da vida corrente. Em suas palavras:

Tais preocupações com a incompatibilidade, a incomensurabilidade, ou contradição entre relações de intimidade e relações impessoais são duradouras e persistentes. Desde o século XIX, os analistas sociais repetidamente pressupõem que o mundo social organiza-se ao redor de princípios incompatíveis e que competem entre si: Gemeinschasft e Gesellschasft, atribuição e êxito pessoal, sentimento e racionalidade, solidariedade e interesse próprio (ZELIZER, 2011, p. 30).
\end{abstract}

Essa visão de mundo dualista e antagônica entre economia e relações íntimas, Zelizer aborda, para desconstruí-la, a partir do que ela intitula de teoria das esferas separadas e dos mundos hostis. A primeira referese à ideia de que há dois domínios distintos no mundo social, os quais obedecem lógicas e princípios diferentes. Ao passo que racionalidade, eficiência, impessoalidade e planejamento formariam os atributos e princípios que organizam o mundo da economia, o outro, o mundo expressivo e acalentado das relações interpessoais seria orientado e formado pela solidariedade e pelos sentimentos e significados profundos resultantes do envolvimento emocional e pessoal dos indivíduos entre si (ZELIZER, 2009).

A teoria dos mundos hostis, por sua vez, realça os aspectos valorativos ligados às consequências caso esses "dois mundos" ou esferas entrem em contato. Segunda essa visão, a esfera econômica e a intimidade são uma ameaça constante uma à outra. O contato entre elas redunda, irremediavelmente, numa contaminação e inanição mútua, num abalo dos 


\section{Economia versus intimidade: uma alternativa via as sociologias de Viviana Zelizer e Eva Illouz}

seus fundamentos. A colonização da vida íntima pelo mercado, entendido em seus aspectos abstratos e racionalizadores como mecanismo neutro de formação e coordenação de preços entre atores anônimos, adulteraria, atrofiaria e empobreceria necessariamente as formas de relações humanas mais expressivas, nobres e autênticas. Isto é, aquelas mediações humanas exigentes de afetos e solidariedade em vez de eficiência, cálculo, competitividade e lucro. Da mesma maneira, a introdução dos sentimentos, da solidariedade e da intimidade nas transações racionais teria como correlato consequências nefastas para o funcionamento e consecução dos fins da esfera econômica: ineficiência, favoritismo, corrupção, etc..

Portanto, diagnostica Zelizer:

Nesta perspectiva, existe uma aguda divisão entre as relações sociais íntimas $\mathrm{e}$ as transações econômicas, tornando qualquer contato entre as duas esferas moralmente contaminado. Dessa forma, a intimidade só prospera se as pessoas erigem barreiras eficazes em torno dela. Assim, continua o raciocínio, sistemas sociais bem ordenados mantêm os domínios separados (ZELIZER, 2009, p. 238).

No tratamento, histórica e empiricamente subsidiado, desta tensão fundamental entre economia e moral, entre dinheiro e intimidade ${ }^{10}$, Zelizer esforça-se para apreender como, no cotidiano, as pessoas resolvem e ajustam suas relações e práticas de intercâmbio com base em seus valores e relações sociais. Para a autora, nem a penetração do mercado e da

\footnotetext{
${ }^{10}$ Neste ponto, podemos vislumbrar a relação ambígua, fecundamente crítica, da NSE com o legado dos clássicos. Ao mesmo tempo em que os clássicos legaram importantes ferramentas intelectuais e análises dos fatos econômicos, tomando estes como centrais para a sociologia e para explicação da sociedade e da cultura moderna, eles, também, por outro lado, legaram alguns obstáculos na forma de pré-noções e dicotomias capazes de enviesar a compreensão e as análises da vida econômica capitalista. As ideias de fetichismo (Marx), instrumentalização e objetificação da cultura e das relações sociais (Simmel), perda de sentido (Weber) e anomia (Durkheim) contém elementos que podem conduzir à interpretações enviesadas, duais e fatalistas, tal qual critica e alerta Zelizer em sua obra.
} 


\begin{abstract}
Alyson Freire
economia reduzem a sociedade e as relações sociais aos imperativos da commodificação e do instrumentalismo nem as transações econômicas ou o mercado são desprovidos de códigos culturais e de significados sociais e pessoais dos atores participantes. Muito pelo contrário, em seu cotidiano, as pessoas assumem um trabalho relacional por meio do qual empregam a atividade econômica para criar, manter e renegociar laços íntimos com os outros, assim como encontram no afetivo e na intimidade bases com as quais organizam e fundamentam sua vida econômica.

Para Zelizer, as pessoas participam rotineiramente do processo de diferenciar relações sociais significativas, de modo que, tal empenho contempla também suas transações econômicas em relação aos seus laços de intimidade. Para isso, elas usam e combinam diferentes sistemas de pagamento, símbolos, rituais e práticas para criar, definir, afirmar, contestar e derrubar as distinções, de acordo com a transação social e o relacionamento íntimo em questão:
\end{abstract}

Quando as pessoas lutam por pagamentos, é claro que costumam discutir o valor do dinheiro devido, mas é impressionante a frequência com a qual discutem a forma de pagamento e sua propriedade para a relação em questão. Discutem, por exemplo, as distinções entre pagamentos como indenização, direito ou doação (ZELIZER, 2011, p. 33).

Numa perspectiva mais realista e menos inflamada de crítica social, a socióloga argentina confere aos significados culturais compartilhados, à criatividade e à prática cotidiana das pessoas uma importância crucial na definição dos sentidos das transações e das práticas de mercado. Nesse sentido, pensa a autora, os relacionamentos íntimos que envolvem união, atenção, trocas afetivas e de informações biográficas privilegiadas, tais como compras grandes, orçamentos familiares, provisão de cuidados de saúde, noivados e presentes cerimoniais, entre outras mais, implicam transações econômicas, as quais são, muitas vezes, essenciais para a manutenção dos vínculos de intimidade. Portanto, conclui Zelizer: “a atividade econômica é integral e essencial a uma ampla gama de relações íntimas, mas a presença da intimidade empresta um significado especial à atividade econômica" (ZELIZER, 2011, p. 237). 


\section{Economia versus intimidade: uma alternativa via as sociologias de Viviana Zelizer e Eva Illouz}

Não são as redes sociais que interessam a socióloga, como em Granovetter e seus seguidores, mas o que as pessoas fazem de significativo quando envolvidas em relações econômicas, isto é, os processos de negociação de sentidos e interações particulares que ocorrem dentro das atividades econômicas de produção, consumo, distribuição e transferência de ativos.

Desse modo, Zelizer concorda que intimidade e racionalidade econômica suscitam efeitos recíprocos, mas não como preconiza, normativamente, a teoria dos mundos hostis e das esferas separadas. Para os atores sociais, defende a socióloga argentina, esses efeitos e consequências são contextuais e servem como suportes e marcadores de inteligibilidade do conteúdo e das distinções qualitativas dos relacionamentos e das transações.

As distinções qualitativas operadas pelas pessoas nas relações econômicas, segundo Zelizer, extrapolam a negociação acerca da definição do preço e da quantidade. Elas estabelecem fronteiras, ajustes e combinações a partir da quais organizam e balizam para si mesmas e para os outros os sentidos das relações econômicas e dos laços afetivos em que estão envolvidos, servindo-se dos significados compartilhados e da própria rotina para criar, definir e sustentar as combinações e limites de tais relações e laços.

Dessa maneira, conclui Zelizer: "A questão, portanto, não é se parceiros íntimos podem ou devem participar de transações econômicas, mas que tipos de transações econômicas combinam com as relações íntimas" (ZELIZER, 2011, p. 236).

Em vez de construir diagnósticos sociológicos lamuriosos sobre as consequências culturais e psicológicas acerca da inserção do dinheiro nas relações íntimas, Zelizer problematiza o modo pelo qual o dinheiro é usado e negociado em termos de atribuição de sentidos éticos em interações sociais concretas. Em outras palavras, ela examina os sentidos com os quais as pessoas elaboram as fronteiras, as obrigações recíprocas e as suas narrativas de justificação, o intenso trabalho relacional a partir do qual elas tentam organizar e fazer funcionar as transações, a um só tempo e numa via dupla, econômicas e íntimas em que elas estão enredadas no curso da vida social, ou em momentos dramáticos desta, como num caso de divórcio ou de disputa judicial por indenização judicial ou herança. 
A agência e reflexividade dos atores são aspectos essenciais no esquema de análise de Zelizer; constituem uma condição indispensável para abordar e explicar as intersecções produzidas nas interações entre a afetividade e o econômico. Não estamos diante de atores passivos, de meros suportes das estruturas sociais, ou de vítimas das forças econômicas arrasadoras.

Para fundamentar sua crítica à teoria das esferas separadas e dos mundos hostis, Zelizer examina como em mercados concretos existem laços diferenciados. A esse respeito, afirma Zelizer: "Em todos os tipos de situações, das predominantemente íntimas às predominantemente impessoais, as pessoas diferenciam fortemente vários tipos de relações interpessoais, caracterizando-as com distintos nomes, símbolos, práticas e meios de troca" (ZELIZER, 2009, p. 240).

Nesse sentido, sustenta a autora, encontramos densas redes pessoais de patrões e clientes no interior de grandes corporações, como, também, descobrimos no trabalho doméstico, laços que unem seus participantes com extensas cadeias de agentes externos de produção, distribuição e consumo. Sejam quais forem os arranjos socioeconômicos e as atividades de transação, as pessoas estão envolvidas e engajadas em múltiplos conjuntos de relações sociais, os quais elas buscam ordenar e administrar, de maneira árdua e conflituosa, ressalte-se, a fim de negociar as combinações e distinções qualitativamente significativas que definem os termos das relações e aquilo que a sustentam (ZELIZER, 2009).

A sociologia econômica de Zelizer apresenta uma dupla crítica da compreensão de mercado, tal como encontramos nos manuais de economia e nas vertentes mais críticas das ciências sociais. Primeiro, o mercado não é apenas feito por mecanismos impessoais de formação de preço ou pela racionalidade de meios e preferências de atores anônimos; ele está inserido e atravessado por laços sociais, interações humanas e crenças compartilhadas. Segundo, esses fatores racionalizantes e impessoais de coordenação não são necessariamente forças irremediáveis de corrupção e perversão das relações e sentimentos humanos. Portanto, para Zelizer, o mercado não está imune aos valores morais e significados sociais que afeiçoam uma cultura numa determinada época nem blindado contra a subjetividade e as relações sociais concretas dos atores participantes nas relações de intercâmbio. 


\section{Economia versus intimidade: uma alternativa via as sociologias de Viviana Zelizer e Eva Illouz}

As transações econômicas relacionam-se - e modificam-se - vis-à-vis com a cultura e com as relações interpessoais porque elas estão atravessadas por essa complexidade significativa de valores, significados e afetos, que elas, aliás, ajudam, também, a construir, manter e transformar. A obra de Zelizer ensina-nos que os laços afetivos e as interações entre as pessoas, historicamente e culturamente situados, são importantes e decisivos para entender o desenvolvimento do mercado e a dinâmica de transações comerciais concretas.

\section{Eva Illouz: Mercado, Afetos e Cultura}

Ainda que pouco conhecida no Brasil, Eva Illouz é, entre os sociólogos contemporâneos, uma autora renomada e relevante, como atestam suas premiações; Consuming the Romantic Utopia: Love and the Cultural Contradictions of Capitalism e Oprah Winfrey and the Glamour of Misery: An Essay on Popular Culture - ambos premiados como o "Melhor Livro" pela Associação Americana de Sociologia, respectivamente em 2000 e 2005 nas seções "Emoções" e "Cultura".

A socióloga marroquina Eva Illouz não é exatamente uma autora autodeclarada como pertencente às fileiras da NSE, como Viviane Zelizer. $\mathrm{Na}$ verdade, seu trabalho consiste numa sociologia da cultura, dedicada a investigar a história da vida emocional na modernidade, lida através das relações entre emoções, capitalismo e o discurso psicológico. Mais precisamente, os rituais de consumo do amor romântico, as formas de racionalização do sofrimento emocional pelas terapias e literatura de autoajuda, a gestão mercantil das emoções no ambiente de trabalho. Suas pesquisas, portanto, inscrevem-se numa investigação sociológica dos modos institucionais e culturais de mobilização dos afetos na modernidade, com um particular acento sobre o entrelaçamento da vida emocional do indivíduo moderno com a racionalidade econômica, a cultura do consumo e o saber psicológico (ILLOUZ, 2008, 2009, 2011).

Illouz fundamenta suas reflexões com base num duplo diagnóstico sociológico acerca de uma das singularidades societárias que caracterizam o desenvolvimento histórico e social da modernidade tardia. Em primeiro lugar, de acordo com Illouz, no decorrer do século $\mathrm{XX}$, as esferas culturais, da vida afetiva e econômica entrelaçaram-se de uma forma cada vez mais crescente e sistemática, exercendo efeitos recíprocos e moldando e influenciando umas às outras, e com profundas consequências subjetivas 


\begin{abstract}
Alyson Freire
sobre o "eu" e as relações afetivas, isto é, sobre o modo pelo qual os indivíduos contemporâneos lidam e se relacionam com sua vida emocional.

Em segundo lugar, para Illouz, a história do século XX é uma história do crescimento da concentração sistemática e institucional sobre a vida afetiva e as emoções dos indivíduos enquanto uma dimensão socialmente marcante e relevante para intervenção nas relações interpessoais nos mais variados âmbitos da vida social, a família, a empresa, a escola, os meios de comunicação. Os gestores no ambiente do trabalho, os produtores culturais, ativistas na sociedade civil ou os próprios indivíduos na família e em suas relações pessoais passaram a dedicar cada vez mais esforços e atenção para assimilar a sua atividade e experiência social esta disposição como uma verdadeira bússola para suas decisões, autocompreensões e aspirações (ILLOUZ, 2011).

É em função dessas hipóteses que Illouz constrói suas pesquisas. Nelas, a autora busca compreender o papel dos esquemas compartilhados de significados culturais no engendramento de uma forma de sujeito baseado na exploração emocional de seus afetos, cotidiano e relacionamentos interpessoais. Esses esquemas, como o discurso psicológico e de autoajuda, mas também a cultura de consumo, a racionalidade do mercado capitalista e a internet, são entendidas como práticas sociais institucionalizadas que organizam e coordenam as emoções e a vida afetiva dos indivíduos, produzindo formas de compreensão e apresentação da própria subjetividade.

Parte significativa da obra de Illouz trabalha, com rigor e imaginação sociológica notável, questões que se encontram nas interseções entre cultura, afetos e economia. Os vínculos existentes entre afetos, cultura e economia constituem o principal desafio ao qual seu pensamento e esforços se dirigem. Para isso, nossa autora lança mão de aportes teóricos que vão dos Estudos Culturais à Escola de Frankfurt, passando por Pierre Bourdieu, à antropologia interpretativista de Clifford Geertz e o pragmatismo americano de Dewey.

É nesse sentido que, com segurança, podemos situar os trabalhos de Illouz no campo da reflexão sociológica sobre os laços entre racionalidade econômica e vida afetiva. Para a autora, o estudo da vida afetiva dos indivíduos sob uma perspectiva sociológica justifica-se porque as emoções e os sentimentos são inseparáveis dos esquemas culturais e das práticas sociais institucionalizadas de uma sociedade. São em função desses últimos
\end{abstract}




\section{Economia versus intimidade: uma alternativa via as sociologias de Viviana Zelizer e Eva Illouz}

que as emoções emergem, ganham forma, intensidade e significado particulares. Ou seja, as emoções não se reduzem aos seus aspectos fisiológicos e bioquímicos particulares, elas, também, possuem condicionantes culturais, históricos e sociais relevantes para sua manifestação e explicação. Em outras palavras, os indivíduos sentem, também, condicionados por seu contexto social.

Para Illouz, os afetos compõem uma das dimensões motivacionais da ação. Eles são como uma "energia interna" impulsionadora do agir, e que, na prática, se entrelaçam com significados e padrões culturais, relações sociais e instituições (ILLOUZ, 2011 p. 9). É por essa razão que os afetos, segundo Illouz, podem iluminar aspectos pouco explorados da organização social e econômica de uma sociedade. Desse modo, a autora assume a relação do "eu" com suas emoções como um fenômeno sociologicamente relevante e condicionado por mecanismos sociais, como as instituições e os repertórios culturais compartilhados, os quais cumpre estudar - em suas relações com as emoções - seriamente de um ponto de vista empírico e teórico.

Vejamos, então, como suas análises consistem em mais um dos investimentos sociológicos a partir dos quais podemos confrontar as dicotomias entre economia e afetos, mercado e cultura.

Sua obra de estreia, Consuming the Romantic Utopia: Love and the Cultural Contradictions of Capitalism, aborda como o ideal e a experiência do amor romântico adquiriram forma como cultura, isto é, enquanto uma representação generalizada e compartilhada socialmente, graças à apropriação do mercado, em particular na esfera do consumo e da cultura de massa.

Nos primeiros decênios do século $X X$, a noção e a prática do ideário do amor romântico sofrem uma transformação fundamental. Á medida em que este é incorporado pelo consumo e à cultura popular por meio da publicidade de roupas, cosméticos, cinema, ficção popular e revistas femininas, os aspectos religiosos, emancipatórios - questionamento das normas e convenções sociais, relações hierárquicas entre pais-filhos, noção de casamento como negócio familiar - e trágicos do ideário do amor romântico do século XIX cedem lugar para aspectos que ressaltam a "felicidade pessoal" e a autorrealização individual mediada pela fruição em consumir e comprar certos produtos e desfrutar de eventos e lugares - 


\begin{abstract}
Alyson Freire
viagens, jantares, lazer, trocas de presente - como modo de intensificar e comunicar os sentimentos e a ligação autêntica com o parceiro.

A esfera do consumo oferece, portanto, o lastro material e simbólico para viver a experiência do amor romântico, quer dizer, a representação cultural compartilhada acerca do amor nas sociedades modernas. $\mathrm{O}$ amor, com efeito, não constitui um mero sentimento humano, senão uma linguagem cultural cuja narratividade, performance e experiência necessitam da objetividade social na forma de instituições, signos e rituais sociais.

Por outro lado, mais do que uma prática de indivíduos isolados em busca de satisfazer necessidades básicas, o consumo é, nesse aspecto, uma esfera da atividade humana fundamental na mediação das relações entre economia e cultura. Os bens e serviços de consumo estabelecem e sustentam não apenas relações sociais mas, também, sentimentos e afetos conferindo-lhes formas materiais, cenários e interações culturalmente significativas para sua expressão emocional e experiência.

Illouz não está, aqui, muito distante das elaborações de Mary Douglas e Baron Isherwood em seu importantíssimo livro O Mundo dos Bens. Ou seja, ela trata o consumo de bens e serviços como uma atividade significativa e comunicativa capaz de materializar e estabilizar os significados, valores e as categorias de classificação de uma cultura. Os bens e serviços de consumo, nas sociedades capitalistas avançadas, funcionam como acessórios e cenários rituais por meio dos quais representações culturais realizam-se eficazmente, inclusive no plano dos sentimentos e dos afetos dos indivíduos. Como hão dito a antropóloga e o economista: "a função essencial do consumo é a sua capacidade de dar sentido" (DOUGLAS \& ISHERWOOD, 2004, p. 108).

Em continuidade, no livro de Illouz sobre o amor romântico e o consumo, não se trata, portanto, como seria corrente imaginar quando se pensa as relações entre amor e capitalismo, do impacto destruidor e nocivo do segundo sobre o primeiro. Num tom provocativo, Illouz afirma, aliás, que amor romântico e mercado capitalista formam um "par bem resolvido". Deste modo, trata-se de compreender as formas e os mecanismos pelos quais se deram este encontro mutuamente produtivo entre as emoções românticas com a cultura, com a economia e com a organização do capitalismo avançado. Em outras palavras, identificar as
\end{abstract}




\section{Economia versus intimidade: uma alternativa via as sociologias de Viviana Zelizer e Eva Illouz}

afinidades eletivas entre o ideal do amor romântico e a cultura de consumo do capitalismo avançado.

À princípio nada pode ser mais antagônico e avesso um ao outro, do que o sentimento e experiência afetiva que chamamos "amor" e o sistema de organização do trabalho de acumulação ilimitada, o capitalismo. Tal contradição não passa despercebida por Illouz. Nesse sentido, considera a socióloga marroquina a respeito das relações entre amor romântico e a organização capitalista:

O amor romântico não é racional, mas irracional, não é lucrativo, mas gratuito, não utilitário, mas orgânico, e não é público, mas privado. Em síntese, o amor romântico parece evadir as categorias tradicionais segundo as qual se concebe o capitalismo. Tanto no âmbito acadêmico como na cultura popular e na esfera do "senso comum": o amor romântico se eleva acima do intercâmbio comercial e, inclusive, mais além da ordem social em geral (ILLOUZ, 2009, p. 19).

Porém, o argumento central que Illouz defende ao longo do livro consiste exatamente em demonstrar as afinidades eletivas entre amor romântico e o capitalismo avançado, descrevendo, num relato historicamente informado, como o mercado capitalista funcionou como o motor preponderante na estruturação e dinâmica das relações e encontros amorosos na sociedade norte-americana. A apropriação do amor romântico pela esfera do consumo ao longo do século $\mathrm{XX}$, institucionalizou a experiência romântica como um bem cultural e um ideal de vida socialmente compartilhado e perseguido pelas classes sociais, sobretudo as classes médias urbanas e mais escolarizadas.

O entrelaçamento entre mercado capitalista e amor romântico se deu em decorrência de um duplo processo cujo lugar confunde-se com a formação da esfera do consumo de massa nos Estados Unidos ao longo do século XX: por um lado, a codificação da experiência romântica ou do romance pelos repertórios de imagens, símbolos e narrativas criados pelo cinema, a publicidade, as revistas femininas, os romances de bolso, o que Illouz intitula de "romantização dos bens de consumo". De outro, o que a 
autora conceitua como "mercantilização do romance", isto é, a esfera do consumo como lócus e desencadeador privilegiados da vivência do romance e dos sentimentos românticos.

O mercado capitalista, com seus espaços, bens e serviços, formam as molas que convertem os rituais românticos em rituais de consumo. De acordo com Illouz, este "par bem resolvido" entre amor romântico e capitalismo forma o complexo institucional e simbólico da experiência amorosa dos indivíduos na modernidade tardia. Dito de outro modo, as conexões entre a cultura de consumo do capitalismo avançado e o ideal do amor romântico criaram uma rede de espaços sociais rotineiros e de significados compartilhados que introduz os indivíduos em cenários e rituais nos quais eles, para desenvolverem suas performances eróticoamorosas e materializarem e comunicarem suas emoções, precisam das mediações do mercado capitalista. A experiência amorosa, na modernidade tardia, é inseparável dos espaços, práticas sociais e da linguagem da cultura do consumo (ILLOUZ, 2009).

Este processo de fusão entre romance e cultura de consumo, que Illouz intitula de "economia política do romance", não está livre de ambiguidades. De acordo com Illouz, a incorporação do amor romântico à cultura de consumo e ao mercado capitalista instila nas relações amorosas as contradições, repertórios e desigualdades que afeiçoam e constituem este último, em particular as relações de classe. As desigualdades constitutivas do mercado e das classes sociais foram transferidas para ligação e as relações românticas em si. Isso significa que as interpretações da experiência amorosa e os usos dos objetos e mercadorias românticos são estratificados, quer dizer, variam, para Illouz, em termos da posição e do capital econômico e cultural das classes sociais para a apropriação dos signos e rituais de consumo da utopia do amor romântico.

Podemos observar tanto em Zelizer quanto em Illouz, uma concepção de mercado bastante próxima daquela que Abramovay, comentando sobre o conceito de mercado utilizado na NSE, afirma ser característica das análises dessa corrente: “É o mercado como fato histórico localizado geograficamente e composto por entidades vivas, encarnadas, em suma, como instituição - não apenas como mecanismo geral de coordenação -, que tende permanentemente a ser ofuscado" (ABRAMOVAY, 2004, p. 36). 


\section{Economia versus intimidade: uma alternativa via as sociologias de Viviana Zelizer e Eva Illouz}

O que se troca no mercado são mais do que transações econômicas, são também trocas sociais complexas formadas por afetos e sentidos culturais permanentemente trabalhados e redefinidos pelos atores para definir sua posição e a dos outros no interior de relacionamentos sociais variados. A construção e funcionamento dos mercados envolvem, portanto, o recurso ou a reformulação de repertórios culturais prévios cujos elementos cognitivos proporcionam aos indivíduos formas de classificação e de interpretação do mundo.

O mercado é modelado culturalmente pelos processos de negociação de sentidos em que instituições e consumidores estão implicados. Os processos econômicos não são definidos exclusivamente por mecanismos impessoais de formação de preços e comportamentos racionais e instrumentais de atores anônimos que se ignoram como pessoas concretas, são antes de qualquer coisa formados por interações humanas inseridas, atravessadas e moldadas por marcos culturais dotados de sentidos: laços sociais, sentimentos e crenças compartilhadas.

Na obra de Illouz isso pode ser encontrado numa coletânea de conferências, ministradas no histórico Instituto de Pesquisas Sociais em Frankfurt por ocasião do aniversário de Theodor Adorno, em que a socióloga realiza um balanço sistemático dos interesses, preocupações e perspectiva teórica que conduziram o seu trabalho até então, assim como os seus novos interesses. Dentre estes, a socióloga persegue o que intitula da emergência de um novo estilo afetivo de mobilização do "eu" e dos afetos, calcado no entrelaçamento entre o saber e as técnicas psicológicas com a racionalidade da empresa capitalista, formando o que autora intitula de "capitalismo afetivo". Em suas palavras, "uma cultura em que os discursos e práticas afetivos e econômicos moldam uns aos outros" (ILLOUZ, 2011, p.12).

Nessas conferências, Illouz aborda a institucionalização da psicologia e da linguagem terapêutica no mundo do trabalho e cooperativo enquanto uma importante ferramenta na seleção, gestão e avaliação do desempenho dos trabalhadores. Num contexto de transformações institucionais do capitalismo, na transição entre a chamada época de ouro do capitalismo e a formação de uma economia de serviços, os psicólogos operaram como experts em desenvolver ideias e procedimentos a fim de aprimorar as relações humanas no mundo das organizações, substituindo ou rivalizando com o discurso da racionalidade técnico- administrativa dos 
engenheiros. Essa intervenção dos psicólogos na gestão do processo de produção e organização do trabalho redefiniu a hierarquia de competências profissionais socialmente desejáveis e exigidas pela empresa capitalista. $\mathrm{O}$ que Illouz quer nos mostrar é a emergência de uma aliança cultural entre racionalidade capitalista e o ethos terapêutico, isto é, um modo de gerir, intervir e preocupar-se com a vida afetiva e com o "eu", profundamente marcado e sustentado por categorias e técnicas psicológicas.

O centro gravitacional do bom comportamento produtivo e profissional - de gestores e trabalhadores - reorienta-se em direção às capacidades e atributos atrelados à personalidade e às emoções, como a "comunicação", "cooperação", "empatia" ou "escuta atenta", entre outras. A penetração do código terapêutico no mundo do trabalho interliga as competências profissionais tradicionais com a vida emocional dos gestores e trabalhadores. Nesse sentido, o êxito na gestão e no trabalho passa necessariamente pela gestão e autogestão competente das emoções dos gestores e trabalhadores na instituição.

$\mathrm{O}$ agenciamento entre psicologia e empresa capitalista introduz, de modo radical, os afetos e os conteúdos emocionais no interior da dinâmica do comportamento econômico e da ação instrumental. Os conteúdos emocionais e os dilemas típicos das relações interpessoais transformam-se em variáveis relevantes para o bom desempenho do comportamento produtivo e profissional no âmbito das empresas e organizações. Em contrapartida, também a vida afetiva e as relações interpessoais são impregnadas pelos repertórios do mercado e da lógica da racionalidade econômica - desempenho, eficiência, cálculo, equilíbrio, competição, vantagens - os quais passam a funcionar como verdadeiras grades de leitura e ideais morais da vida afetiva dos indivíduos (ILLOUZ, 2011).

Em outras palavras, de acordo com Illouz, emerge um repertório cultural que coloniza as esferas do trabalho e das relações afetivas segundo discursos que ligam estreitamente o sujeito econômico às emoções e estas últimas à ação instrumental. Portanto, a interdependência crescente entre a racionalidade capitalista e a racionalidade psicológica produz, no cotidiano dos indivíduos, o entrelaçamento entre o econômico e o emocional.

Para Illouz, é, com efeito, um equívoco opor em lados diferentes, organização econômica e emoções. A história e o desenvolvimento do capitalismo avançado na modernidade tardia mostram, antes, o estreitamento e reforço mútuo entre as técnicas de gestão do trabalho e as 


\section{Economia versus intimidade: uma alternativa via as sociologias de Viviana Zelizer e Eva Illouz}

técnicas de gestão da subjetividade e dos afetos, quer seja para o bom desempenho nas empresas quer seja para lograr uma vida emocionalmente saudável, realizada e autônoma.

Vale frisar que, dito estreitamento não se trata de uma colonização de mão única, mas de um entrelaçamento entre racionalidade econômica e vida afetiva que produz efeitos positivos recíprocos na experiência social e na relação do eu com suas emoções. E é na tese do papel da cultura, das instituições e dos bens do consumo para estabilizar e mediar a experiência do amor romântico como ritual ou na tese do papel da psicologia na construção e consolidação de uma cultura afetiva particular responsável por reconfigurar a linguagem e a experiência da individualidade, inclusive no âmbito da ação econômica, que a socióloga marroquina busca demonstrar a superação dessa pretensa dicotomia entre economia e intimidade.

\section{Considerações Finais}

Os empreendimentos sociológicos de Viviana Zelizer e Eva Illouz são contundentes a respeito de como redescrever as relações e pré-noções dicotômicas entre racionalidade e emoções e mercado e cultura. Tanto em Zelizer quanto em Illouz, a análise do econômico não se restringe aos mecanismos e processos supostamente exclusivos e sistêmicos da economia. As relações e ações econômicas surgem, desenvolvem-se e transformam-se em função das nossas relações com os outros e dos códigos culturais e morais em questão num determinado contexto de práticas sociais. Os ingredientes e mecanismos das relações humanas, no entanto, não se subordinam nem se reduzem, como na análise econômica convencional, à racionalidade dos interesses e das preferências individuais, mas implicam emoções, a negociação do status das relações interpessoais, os códigos culturais compartilhados, intimidade, dilemas éticos, identidade. O que essas sociólogas nos mostram é que toda essa complexidade das relações sociais importa seriamente para o entendimento e explicação das atividades econômicas e para a formação e dinâmica dos mercados.

Zelizer busca na história e na sociologia econômica aportes para construir um novo marco de análise da racionalidade da vida econômica em que esta seja enxergada como sendo "influenciada por crenças partilhadas, por normas monitoradas e aplicadas por mecanismos que 
surgem das relações sociais" (ABRAMOVAY, 2004, p. 36). Illouz, por sua vez, valendo-se da história e de uma teoria da ação pragmatista e culturalista, explicita as afinidades eletivas e as relações de compatibilidade onde o senso comum corrente e douto sedimentou antagonismo e aversão recíproca.

Encontramos em ambas as sociólogas, o papel central destinado à capacidade significativa dos indivíduos na definição dos sentidos morais das relações econômicas e afetivas em que eles estão envolvidos. Mais ainda: as relações mediadas dos indivíduos com os seus próprios dilemas emocionais constituem uma chave analítica relevante na investigação sociológica, capaz de trazer à luz aspectos importantes, e muitas vezes ignorados, do mundo social: por exemplo, os significados e consequências de um conjunto de transações econômicas para a experiência amorosa dos indivíduos. Em síntese, a relação do "eu" com suas emoções, a interação social e os significados culturais compartilhados moldam aspectos indispensáveis da vida econômica. Essa é uma das grandes lições que podemos extrair da obra, ainda em desenvolvimento, dessas duas importantes autoras.

Com essa tese, Zelizer e Illouz ambicionam, por caminhos teóricometodológicos distintos, superar o corte normativo e analítico arbitrário que produziu uma divisão acentuada entre economia e sociedade e, sobretudo, entre a primeira e as relações íntimas - sem com isso, diga-se, almejar converter todas as interações sociais em trocas econômicas passivas de serem analisadas mediante a lógica, a dinâmica e as operações dos mercados. Isso exige, com efeito, uma atenção sociológica aos repertórios culturais e as práticas sociais rotinizadas com os quais os indivíduos realizam a mediação de suas relações com o mercado e as transações econômicas em que estão envolvidos. Do mesmo modo que, por outro lado, exige que o analista atente ao modo como as práticas e repertórios do mercado incidem sobre os laços sociais e sentimentos das pessoas sem necessariamente deturpá-los e destruí-los. Neste ponto, Illouz assume uma veia mais crítica e sensível às relações de dominação que os mecanismos e a linguagem do mercado podem exercer sobre o campo da afetividade e das emoções humanas, produzindo novas concepções, formas de sujeição e desigualdades (ILLOUZ, 2011).

Nas análises da socióloga argentina não se trata, por sua vez, de desacreditar os diagnósticos críticos da modernidade produzidos pelos 
clássicos a propósito das consequências profundas e perversas da dominação da racionalidade econômica sobre as demais esferas da vida social e sobre a subjetividade. A objeção de Zelizer endereça-se a generalidade desses diagnósticos em favor de uma visão mais nuançada das relações entre vida íntima, cultura e economia, articulando a tessitura dos sentidos negociados que se forma nas práticas sociais rotinizadas das pessoas.

De um modo geral, os trabalhos inspirados na NSE apresentam estratégias analíticas e aportes cuja fecundidade transcende este recente filão da análise sociológica da vida econômica. O ganho, podemos dizer, reverbera para a própria sociologia em geral, isto é, nas intersecções a se produzir com outras especialidades da ciência da sociedade, como nos mostram, a meu ver, os trabalhos de Illouz.

Por fim, os estudos de Zelizer e Illouz ajudam a levar o entendimento da realidade econômica para novos níveis explicativos, na medida em que propiciam e convidam o cultivo de uma atenção teórica e empiricamente disciplinada com respeito às conexões complexas e nuançada das atividades econômicas com outros aspectos relevantes e incontornáveis das relações humanas, ou seja, os sentimentos, a moralidade, a cultura, a vida emocional dos indivíduos. Não obstante os rumos da ciência econômica, esta é uma lição, aliás, que figura, conforme economistas consagrados como Albert Hirschman (1981; 2002) e Amartya Sen (1992), nos primórdios da ciência econômica enquanto uma disciplina que nasce à sombra de uma reflexão ampla e profunda acerca da complexidade das motivações do comportamento humano e das implicações do agir econômico sobre a vida social, a ética e a cultura.

\section{Bibliografia}

ABRAMOVAY, Ricardo. Entre Deus e o Diabo: mercados e interação nas ciências humanas. Tempo Social, vol. 16, n. 2, 2004. Disponível em: http://www.scielo.br/pdf/ts/v16n2a02.pdf.

ALEXANDER, J. O novo movimento teórico. Revista Brasileira de Ciências Sociais, v. 2, n. 4, p. 5-28, jun. 1987. 


\begin{abstract}
Alyson Freire
\end{abstract}
BAUMAN, Zygmunt. Amor líquido - sobre a fragilidade dos laços humanos.Rio de Janeiro: ZAHAR, 2004.

DOUGLAS, Mary; ISHERWOOD, Baron. O mundo dos bens: para uma antropologia

do consumo. Rio de Janeiro: Editora UFRJ, 2004.

DUMONT, Louis. Homo Aequalis: gênese e plenitude da ideologia econômica.

São Paulo. EDUSC, 2000.

DURKHEIM, Emile. As formas elementares da vida religiosa. São Paulo. Martins Fontes, 2000.

ELIAS, Norbert. O Processo Civilizador: uma história dos costumes. Rio de Janeiro: Jorge Zahar, 1994. v.1.

- A Solidão dos Moribundos. Rio de Janeiro: Jorge Zahar Editor, 2001.

FLIGSTEIN, Neil. Mercado como política: uma abordagem políticocultural das instituições de mercado. Contemporaneidade e Educação, n. 9, p. 26-55, 2001.

GRANOVETTER, Mark. Ação econômica e estrutura social: o problema da imersão. RAE electron. [online]. 2007, vol.6, n.1, pp. 0-0. ISSN 16765648. http://dx.doi.org/10.1590/S1676-56482007000100006.

GIDDENS, Anthony. A transformação da intimidade. São Paulo: Ed. Unesp, 1994.

HIRSCHMAN, Albert O. A moralidade e as ciências sociais. Novos Estudos Cebrap. 1981, vol. 1, p. 25-31.

As paixões e os interesses: argumentos políticos a favor do capitalismo antes do seu triunfo. Rio de Janeiro. Record, 2002. 
Economia versus intimidade: uma alternativa via as sociologias de Viviana Zelizer e Eva Illouz

HOCHSCHILD, A. R. The managed heart: commercialization of human feeling. Berkeley, University of California Press, 1983.

ILLOUZ, Eva. Saving the Modern Soul: Therapy, Emotions, and the Culture of Self-Help. Berkeley: University of California Press, 2008.

. El consumo de la utopía romántica. El amor y las contradiciones del capitalismo. Katz Editores, Buenos Aires, 2009.

. O amor nos tempos do capitalismo. Trad. Vera Ribeiro. Rio de Janeiro. Zahar, 2011.

LAGENOHL, Andreas. Elements of a formal sociology of the financial markets. Economic Sociology - The European electronic newsletter. Vol. 12. N 1, 2010. Disponível em: http://econsoc.mpifg.de/archive/econ_12-1.pdf.

LOPES JUNIOR, Edmilson. As potencialidades analíticas da Nova Sociologia Econômica. Revista Sociedade \& Estado. Brasília, vol. 17, n ำ 1 . 2002. Disponível em: http://dx.doi.org/10.1590/S0102-69922002000100004

LUHMANN, Niklas. O amor como paixão. Lisboa: Difel. 1991.

PARSONS, Talcott; SMELSER, Neil J. Economy and Society: a Study in the Integration of Economic and Social Theory. London, Boston, Melbourne and Henley, Routledge \& Kegan Paul, 1956.

PARSONS, Talcott; KROEBER, Alfred. The Profession: Reports and Opinions, American Sociological Review, Vol. 23, 5, Oct., 582-590, 1958.

POLANYI, Karl. A grande transformação: origens da nossa época. Rio de Janeiro, Campus, 2000.

RAUD-MATTEDI, Cécile. A construção social do mercado em Durkheim e Weber: análise do papel das instituições na sociologia econômica clássica. Revista Brasileira de Ciências Sociais - RBCS, vol. 20 (57): 127-142, 2005. 
Alyson Freire

SEN, Amartya. Comportamento econômico e sentimentos morais. Revista Lua Nova, n.25, pp. 103-130. http://dx.doi.org/10.1590/s010264451992000100005, 1992.

SIMMEL, Georg. A filosofia da moda e outros escritos. Lisboa. Texto \& Grafia, 2008.

STEINER, Phillip. A Sociologia econômica. São Paulo: Atlas, 2006.

SWEDBERG, Richard. Sociologia econômica: hoje e amanhã. Tempo Social, 16(2), 2004.

Max Weber e a ideia de Sociologia Econômica. UFRJ, Rio de Janeiro, 2005.

WANDERLEY, Fernanda. Avanços e desafios da Nova Sociologia Econômica. Notas sobre os estudos sociológicos de mercado. Sociedade $\mathcal{E}$ Estado. Nova Sociologia Econômica. Vol 17 (1), Brasilia, UnB. Disponível em: http://www.scielo.br/scielo.php?pid=S010269922002000100003\&script $=$ sci arttext pp:15-38, 2002.

WEBER, Max. Ensaios de Sociologia. Rio de Janeiro: LTC, 2002.

- A "objetividade" do conhecimento nas Ciências Sociais. Trad. Gabriel Cohn. São Paulo. Ática, 2006.

ZELIZER, Viviana. Morals and Markets: The Development of Life Insurance in the United States, Columbia University Press, 1983.

Pricing the Priceless Child: The Changing Social Value of Children. Princeton University Press, 1985.

The Social Meaning of Money: Pin Money, Paychecks, Poor Relief, and Other Currencies, Basic Books, 1994. 
Economia versus intimidade: uma alternativa via as sociologias de Viviana Zelizer e Eva Illouz

Pasados y futuros de la sociología econômica. Apuntes de investigación del CECyP, $\mathrm{n}^{\circ}$ 14, 2008. p. 95-112. Disponível em: http://apuntescecyp.com.ar/index.php/apuntes/article/view/125/110

- Dualidades perigosas. Mana, Rio de Janeiro, v. 15, n. 1, $2009 . \quad$ Disponível em http://www.scielo.br/scielo.php?script=sci_arttext\&pid=S010493132009000100009\&lng=en\&nrm=iso.

A economia do care. Civitas - Revista de Ciências Sociais, Vol. 10, No 3 2010. Disponível em: http://revistaseletronicas.pucrs.br/ojs/index. $\mathrm{php} /$ civitas/article/view/8337.

Vozes, 2011.

A negociação da intimidade. Coleção Sociologia. Petrópolis.

Enviado:

15.08.2014

Aprovado:

08.10.2014 